\title{
Comparision of Post-Menopausal Symptoms in Rural and Urban Women
}

\author{
Santhi Vadugu ${ }^{1}$, Sruthi Kanna ${ }^{2}$ \\ ${ }^{1}$ Assistant Professor, Department Of Physiology, Guntur Medical College, Guntur, India. \\ ${ }^{2}$ Medical Student, SMC, Vijayawada, India.
}

\begin{abstract}
Introduction: Our study includes the comparision of post menopausal symptoms in rural and urban Indian women.

Methods: Random sample of 400 females aged between 45-70 years in post menopausal period were taken as participants for the study. The rural sample was taken from different villages of Guntur district. The urban sample was taken from Guntur city in Andhra Pradesh. To measure the severity of post menopausal symptoms, MRS (Menopausal Rating Scale) is taken as the Health Related Quality of Life scale (HRQoL). MRS includes a structural questioner containing eleven post menopausal symptoms which are divided into three sub scales (somatic, psychological and urogenital).

Results: Severity of Psychological and Urogenital symptoms are well pronounced in rural Indian women compared to urban. However Somatic symptoms are severe in both groups. Compared to rural the overall severity of menopausal symptoms is low in urban.

Conclusion: Improvement of rural health programmes in India are mandatory at this point of time to improve the health quality of rural Indian women. My study suggests lifestyle adjustments of both groups( rural and urban) and stress the importance of creating awareness about the severity of post menopausal symptoms by primary health care staff to the innocent rural women who cares little about their health. Indian government should implement better well being programmes.
\end{abstract}

Keywords: Post menopausal symptoms, HRQoL, Rural health, MRS

\section{Introduction}

The human ovaries become unresponsive to gonadotropins with advancing age and their function declines, so that sexual cycles disappear (menopause). The ovaries no longer secrete progesterone and 17estradiol in appreciable quantities, and estrogen is formed only in small amounts by aromatization of androstenedione in peripheral tissues. ${ }^{[1]}$

Estrogens inhibit secretion of cytokines such as interleukin-1 (IL-1), IL-6, and tumor necrosis factor (TNF-), and these cytokines foster the development of osteoclasts. Estrogen also stimulates production of transforming growth factor (TGF-) and this cytokine increases apoptosis of osteoclasts. ${ }^{[1]}$ After menopause, almost no estrogens are secreted by the ovaries. This oestrogen deficiency leads to (1) increased osteoclastic activity in the bones, (2) decreased bone matrix, and (3) decreased deposition of bone calcium and phosphate.

In some women, this effect is extremely severe, and the resulting condition is osteoporosis. This can greatly weaken the bones and lead to bone fracture. ${ }^{[2]}$ The loss of estrogens often causes marked physiological changes in the function of the body including (1) "hot flushes" characterized by extreme flushing of the skin, (2) psychic sensations of dyspnea, (3) irritability, (4) fatigue, (5) anxiety, (6) occasionally various psychotic states, and (7) decreased strength and calcification of bones throughout the body. These symptoms are of sufficient magnitude in about 15 per cent of women to warrant treatment. If counselling fails, daily administration of oestrogen in small quantities usually reverses the symptoms and by gradually decreasing the dose, postmenopausal women can likely avoid severe symptoms. ${ }^{[2]}$

Oestradiol (synthetic oestrogen) reduces the hot flushes and other symptoms of the menopause. ${ }^{[3]}$

\section{Materials And Methods}

This is a cross sectional comparative study. A total of 400 women are taken under study. Out of them 200 are from different villages in Guntur district, Andhra Pradesh and the remaining 200 are from Guntur city urban area, at the premises of Guntur Medical College. All the participants were given written consent. I asked these women all the questions in my questioner according to Menopausal Rating Scale.

This MRS scale contains

1.Hot flushes, sweating

2.Heart discomfort 
3.Sleep problems

4.Depressive mood

5.Irritability

6.Anxiety

7.Physical and mental exhaustion

8.Sexual problems

9.Bladder problems

10.Dryness of vagina

11.Joint and muscular discomfort.

We have translated the English version of the questioner into local language to facilitate better understanding of the participant. We sought the help of female health workers to interact the women to get accurate data.

\section{Ethics}

Ethics committee of Guntur Medical College and Govt General Hospital, Guntur has issued approval certificate for this study.

Email id-iec.gmc.ggh@gmail.com

\section{Statistical Analysis}

Menopause Rating Scale (MRS) scale is the health related quality of life scale. It measures the severity of menopausal symptoms. Out of the eleven symptoms,

Hot flushes, heart discomfort, sleep problems, muscle and joint problems come under somatic complaints. Depression, irritability, anxiety, physical and mental exhaustion come under psychological complaints.

Sexual problems, bladder problems and dryness of vagina come under urogenital complaints.

These are the three divisions of the total complaints. Severity of each complaint is graded from 0-4. If symptom is not present it is given as 0 grade. Grade 1,2,3,4 are given for mild, moderate, severe, very severe respectively. Total score is taken for each division. Maximum total score is 44 . For somatic complaints, those who obtained score 0-2 were considered to have none or few symptoms,3-4 were considered to be mild and 5-8 have moderate symptoms. ${ }^{[4]}$ For psychological complaints those who obtained score $0-1$ were considered to have none or few symptoms, 2-3 were considered to be mild , 4-6 have moderate symptoms and more than 6 were considered to have severe symptoms. ${ }^{[4]}$ For urogenital complaints, those who obtained score 0 were considered to have none or few symptoms, 1 were considered to be mild , 2-3 have moderate symptoms and more than 3 were considered to have severe symptoms. ${ }^{[4]}$

\section{Result}

\section{Table 1}

\begin{tabular}{|l|l|l|l|}
\hline S.no & Menopausal Symptoms & Rural(\%) & Urban(\%) \\
\hline 1 & Hot flushes, sweating & 80 & 74.28 \\
\hline 2 & Heart discomfort & 48.57 & 37.14 \\
\hline 3 & Sleep problems & 74.28 & 62.85 \\
\hline 4 & Depressive mood & 77.14 & 57.14 \\
\hline 5 & Irritability & 68.5 & 45.71 \\
\hline 6 & Anxiety & 80 & 68.57 \\
\hline 7 & Physical and mental exertion & 65.7 & 51.42 \\
\hline 8 & sexual problems & 57.14 & 37.14 \\
\hline 9 & Bladder problems & 60 & 42.85 \\
\hline 10 & Dryness of vagina & 54.28 & 40 \\
\hline 11 & Joint and muscular discomfort & 88.57 & 77.14 \\
\hline
\end{tabular}

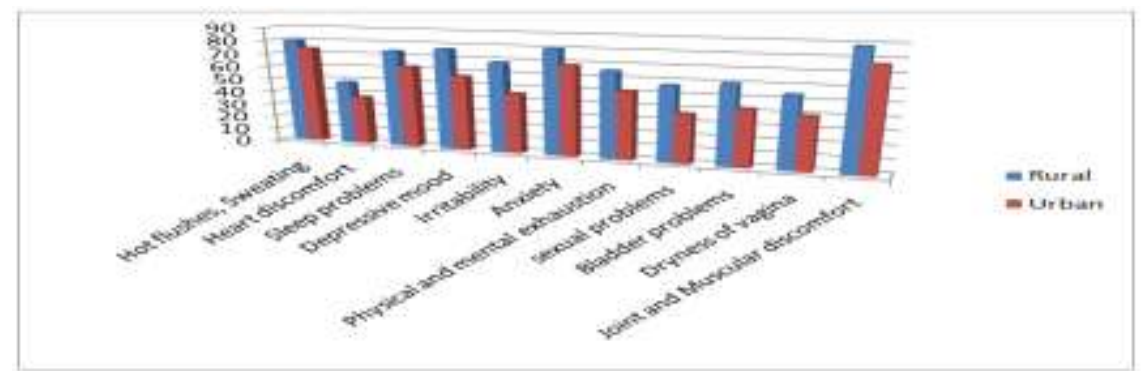




\begin{tabular}{|c|c|c|c|}
\hline S.no & complaints & rural & urban \\
\hline \multirow[t]{4}{*}{1} & Somatic complaints & & \\
\hline & $\square$ None or few $(0-2)$ & 22.85 & 40 \\
\hline & $\square$ Mild (3-4) & 48.57 & 45.71 \\
\hline & $\square$ Moderate (5-8) & 22.85 & 8.57 \\
\hline \multirow[t]{5}{*}{2} & Psychological complaints & & \\
\hline & $\square$ None or few $(0-1)$ & 22.85 & 31.42 \\
\hline & $\square$ Mild (2-3) & 11.42 & 34.28 \\
\hline & $\square$ Moderate (4- 6) & 48.57 & 25.71 \\
\hline & $\square$ Severe $(>6)$ & 17.14 & 8.57 \\
\hline \multirow[t]{5}{*}{3} & Urogenital Complaints & & \\
\hline & $\square$ None or few (0) & 25.71 & 37.14 \\
\hline & Mild (1) & 8.57 & 20 \\
\hline & Moderate $(2-3)$ & 31.42 & 28.57 \\
\hline & $\square$ Severe $(>3)$ & 34.28 & 14.28 \\
\hline
\end{tabular}

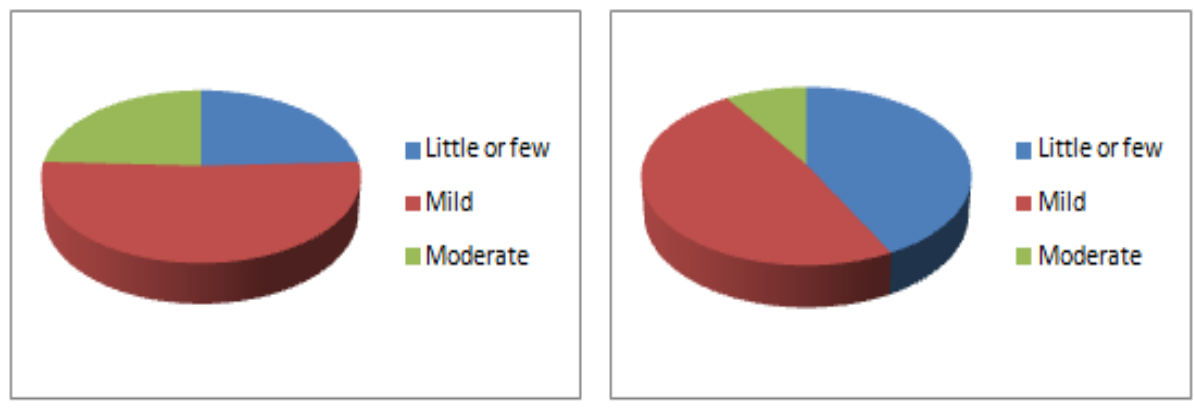

somatic symptoms

Rural

Urban

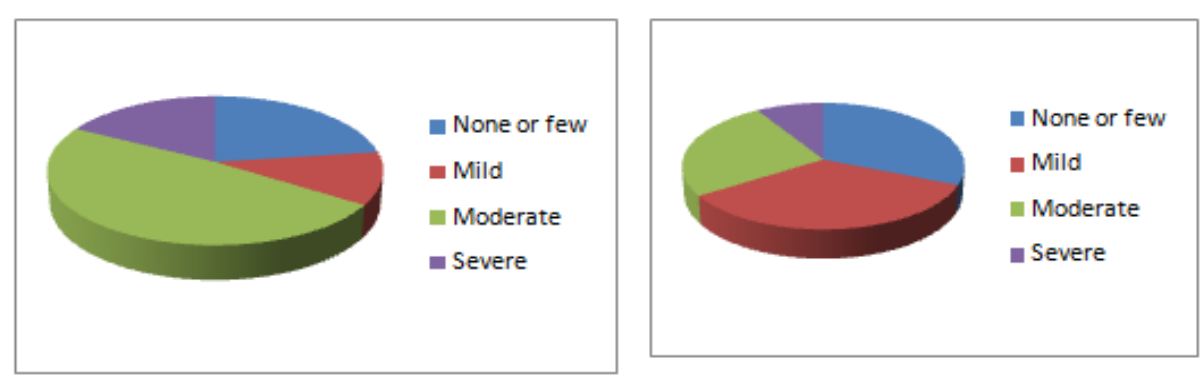

Psychological symptoms 
Table 1 describes that the most frequently complained symptoms by both rural and urban women are joint and muscular discomfort $(88.57 \%$ and $77.14 \%)$, hot flushes and sweating $(80 \%$ and $74.28 \%)$ and anxiety (80\% and 68.57\%). But on comparing both groups they are less severe in urban women than in rural. The next most frequent are sleep problems (74.28\% and 62.85\%), depressive mood $(77.14 \%$ and $57.14 \%)$ in both groups respectively.

Irritability is more in rura $1(68.5 \%)$ whereas it is less in urban $(45.71 \%)$. Sexual problems are more in rura $1(57.14 \%)$ and less in urban $(37.14 \%)$. Less number of participants complained about heart discomfort in both groups $(48.57 \%$ in rural and $37.14 \%$ in urban). About $60 \%$ of rural women complained about bladder problem. Only $42.8 \%$ of urban women are suffering with them. Dryness of vagina is complained only by $40 \%$ of urban and $54.2 \%$ of rural women

Table 2 shows that among the rural women those suffering with somatic symptoms with moderate severity are $22.8 \%$ and those among the urban are $8.5 \%$. Mild symptoms are present in $48.5 \%$ of rural women and $45.7 \%$ in urban women. None or few somatic complaints are present in $22.8 \%$ of rural and $40 \%$ of urban women.

None or few psychological complaints are seen in $22.8 \%$ of rural women and $31.4 \%$ of urban women. Mild symptoms are the complaint in $11.4 \%$ of rural and $34.2 \%$ of urban women. Moderate symptoms are complained by $48.5 \%$ of rural and $25.7 \%$ of urban women. Severity of the psychological symptoms is the complaint in $17.1 \%$ of rural women and $8.5 \%$ of urban women.

Out of the total rural women surveyed severe urogenital complaints are present in $34.2 \%$ and those of urban are $14.2 \%$. Moderate severity is seen in $31.4 \%$ of rural women and $28.5 \%$ of urban women. Mild symptoms are exhibited in $8.5 \%$ of rural and $20 \%$ of urban women. None or few symptoms in $25.7 \%$ rural and $37.1 \%$ in urban women.

\section{Discussion}

Martinez JA in his study states that urban women had a high prevalence of osteoporosis and cardio vascular risk than rural women and rural women experience more hot flushes, depression, joint pain ${ }^{[5]}$. This statement coincides with my study.

According to Dos Santos Tavares DM of brazil, urban showed a greater involvement of the quality of life than the residence in rural area ${ }^{[6]}$. This statement coincides with my study.

According to Sudha Sharma and Neha Mahajan the severity of symptoms was found distressing for rural women ${ }^{[7]}$, which is in correlation with my study.

The study of G K P, Arounassalamme B, states that the most common symptom is muscle pain $(77.2 \%)$ and least common is the dryness of vagina (15\%) among rural women of Puducherry ${ }^{[8]}$. These findings are near to my study.

The study of olaolorul FM of Nigeria states that joint and muscular discomfort was the most common symptom in urban women ${ }^{[9]}$. This statement is in correlation with my study.

A survey by Eman Elsayed Mohammed in Egypt finds that the women suffering with bladder problems is about $38.5 \%{ }^{[10]}$. This finding coincides with my study. He also states that menopausal symptoms are high in rural women of Egypt which is in correlation with my study results.

The studies of Rahman etl in Malaysia ${ }^{[11]}$ and Chedraui $\mathrm{P}^{[12]}$ at Maturitas say that joint and muscular discomfort was the main complaint in about $80 \%$ of women. This finding coincides with mine.

The severity of sleep problems in rural women of Pakisthan according to Syeda Fakhar Batool ${ }^{[13]}$ is about $77 \%$ which is in correlation with my study (74.2\%).

$\mathrm{S}$ Metintas of Turkey states that the rural women in his country is suffering with high score of the menopausal symptoms. We observed the same in india. ${ }^{[14]}$

My finding of hot flushes of about $77.2 \%$ is near to the finding of Neena Chuni's study in Nepal women $(69.7 \%)$. $^{[15]}$

Manal F.Moustafa, in his survey in Qena city observed that there is a decrease in quality of life due to menopause ${ }^{[16]}$. It coincides with my results.

\section{Conclusion}

Female health assistants who work in primary health centres, should address health strategies in rural areas. Government of India should implement more programmes for the improvement of quality of life of rural women. Many studies along with my present study stress the importance of creating awareness of rural stalk about early identification of symptoms of menopause. Thus severity of these in urban is better comparing rural. Life style adjustments are mandatory to improve the quality of life in both groups. 


\section{References}

[1]. Ganong's Review of Medical Physiology, $23^{\text {rd }}$ edition, Pg.no.400.

[2]. Text book of Medical Physiology, Guyton and Hall, Eleventh edition, Pg.no. 1017.

[3]. Text book of Physiology, Prof. A.K.Jain, Third edition, Pg.no.825.

[4]. Perimenopausal and Postmenopausal Complaints in Paramedics Assessed by Menopause Rating Scale in Indonesia, Muhammad Fidel Ganis Siregar1 1(Division of Reproductive Endocrinology and Fertility Medicine - Department of Obstetricss dan Gynecology Faculty of Medicine - University of Sumatera Utara, Indonesia) eISSN: 2279-0853, pISSN: 2279-0861. Volume 13, issue 12 Ver.I (Dec 2014), PP 38-42.

[5]. Urban-rural differences in Spanish menopausal women. Martínez JA1, Palacios S, Chavida F, Pérez M. 1. Rural Remote Health. 2013 Apr Jun;13(2):1865. Epub 2013 May 2.

[6]. Quality of life of elderly. Comparison between urban and rural areas. dos Santos Tavares DM1, Fernandes Bolina A2, Invest Educ Enferm. 2014;32(3):401-13. doi: 10.1590/S0120-53072014000300005.

[7]. Menopausal symptoms and its effect on quality of life in urban versus rural women: A cross-sectional study. Sharma S1, Mahajan N1. Jammu and Kashmir, India. 1. J Midlife Health. 2015 Jan-Mar;6(1):16-20. doi: 10.4103/0976 7800.153606.

[8]. The quality of life during and after menopause among rural women. G K P1, Arounassalame B. 1. J Clin Diagn Res. 2013 Jan:7(1):135-9. doi: 10.7860/JCDR/2012/4910.2688. Epub 2013 Jan 1.

[9]. Experience of menopausal symptoms by women in an urban community in Ibadan, Nigeria. Olaolorun FM1, Lawoyin TO. Nigeria. Menopause. 2009 Jul-Aug;16(4):822-30. doi: 10.1097/gme.0b013e318198d6e7.

[10]. Menopausal symptoms and the quality of life among pre/post menopausal women from rural area in Zagazig Eman Elsayed Mohammed Elsabagh1 and Eman Shokry Abd Allah2,Faculty of Nursing, Zagazig University, Egypt,2010.

[11]. Rahman A, Zainudin S, Kar mun V. Assesment of Menopausal Symptoms Using Modified Menopause Rating Scale Among Middle Age Women in Kuching, Sarawak, Malaysia. Asia Pasific Family Medicine 2010,9:5.

[12]. Chedraui P, Aguirre W, Hidalgo L, Fayad L. Assesing Menopausal Symptoms Among Healthy Middle Aged Women With The Menopausal Rating Scale. Maturitas 57,2007.271-278.

[13]. Perception of Menopausal Symptoms among Educated versus Non Educated Women by Using Menopausal Rating Scale (MRS) Syeda Fakhar Batool, Yasmeen Saggu, Mansoor Ghani Univrsity of Health Sciences Lahore, Lahore, Pakistan, Published Online July 2014 in SciRes. http://www.scirp.org/journal/ojn

[14]. http://dx.doi.org/10.4236/ojn.2014.48063

[15]. Menopause Rating Scale as a screening tool in rural Turkey ,S Metintas, I Arýkan, C Kalyoncu, S Ozalp Eskisehir Osmangazi University Medical Faculty, Public Health Department, Turkey Rural and Remote Health 10: 1230. (Online), 2010 , Available from: http://www.rrh.org.au

[16]. Frequency of symptoms, determinants of severe symptoms,validity of and cut-off score for Menopause Rating Scale (MRS) as a screening tool: A cross-sectional survey among midlife Nepalese women, Neena Chuni1, and Chandrashekhar, Health 2011, 11:30. http://www.biomedcentral.com/1472-6874/11/30.

[17]. Impact of menopausal symptoms on quality of life among women's in Qena City Manal F.Moustafa, Reda R.Ali, Sahar F.El saied, Sayed.A Mohamed Taha Faculty of Nursing- Assuit University. Faculty of Nursing,Faculty of Medicine - South Valley University. e-ISSN: 2320-1959.p- ISSN: 2320-1940 Volume 4, Issue 2 Ver. II (Mar.-Apr. 2015). 